\title{
The relative age effect on anthropometric characteristics and motor performances in Turkish children aged between 8 and 12 years
}

\author{
Ercan Haslofça ${ }^{1 a}$, Fehime Haslofça ${ }^{1}$, and Emine Kutlay ${ }^{1}$ \\ ${ }^{1}$ Ege University, Physical Education and Sports High School, Izmir, Turkey
}

\begin{abstract}
This study was carried out to investigate the effect of relative age on anthropometric properties and motor performance in Turkish children (girls $n=423$, boys $n=601$ ). Anthropometric measurement sites and techniques have been set out by the ISAK (International Society for the Advancement of Kinanthropometry). A group of tests involved in Eurofit Test Battery and other standard tests were used. For each age, the data of those who were born within the first three months and the last three months of the year were compared. The MedCalc Statistics Program was used for the differentiation and variation percentages between two periods were studied $(p \leq 0.001, p=0.05)$. Consequently effect of relative age was observed on anthropometric characteristics and motor performances of Turkish girls and boys between 8 and 12 years old. Researchers, trainers, families, sports managers and organizers are advised to consider Effect of Relative Age.
\end{abstract}

Keywords: relative age effect, anthropometric characteristics, motor performance, children

\section{Introduction}

In order for talented children to reach the most upper steps of mastery, selecting, observing and leading them in early age is very important. Although the required motor, psychological capacity and biometric/anthropometric features for output are valid for all sportive activities [12], their superiority varies according to each sports branch [23] In order to be successful in output level in the future many children must participate in trainings. During this process personal development must be supported by considering the features such as early, normal or delayed developments and also new beginners and advanced children [16].

Motor development usually does not progress with the physical development at same rate. There is a wide variety among the children with same age in terms of structure [11].

\footnotetext{
${ }^{a}$ Corresponding author: ercan.haslofca@ege.edu.tr
} 
Separating athletes into age groups during childhood and adolescence periods has been planned to reduce their maturation differences and to provide and evaluate more balanced sports training [4]. In majority of sports systems athletes are grouped according to chronologic age [18]. The talent identification system for optimum level of competition provides advantages for those who were born rather earlier [21].

The variations between the birthdates of those were born in the same year are defined as relative age differences and their results as the Relative Age Effect (RAE) [2]. The first study that examined RAE in sports was carried out by Grondin, Deschaies \& Nault in [17]. RAE that identifies the general age differences between individuals in each age group may induce important performance differences [25]. In selection year, significant alterations may appear in academic and sportive performances due to growth and development differences between those who were born earlier and later [5]. Even though its effect on adults is small, it is important for children and may result in anthropometric variations [15]. Children who were born early in the year may be more advantageous cognitively, emotionally and physically than those who were born later [7] and RAE gives the impression that it may increase gradually from childhood to adolescence [21]. Those who were born later in the same year may constrain themselves and leave sports [19].

Anthropometric measurements give a good description of the body as a whole. The measurements are those which are routinely taken for a variety of purposes such as monitoring athletes, tracking growth, development, aging and motor performance, and linking physical activity and nutrition interventions to changes in body size, shape and composition [9]. There are studies in the literature that examine the effect of relative age on anthropometric properties [18]. Furthermore, children's abilities such as speed, agility, extremity swiftness, strength and power, endurance, balance and flexibility are measured with the help of standard tests used to determine motor performance and their development is observed. This study was carried out in order to investigate the effect of relative age on anthropometric properties and motor performance in Turkish children in between 8-12 ages.

\section{Method}

This study was carried out with 1024 children (girls $n=423$, boys $n=601$ ) aged between 8 and 12 years who participated in talent scanning tests in June and July 2013. Anthropometric measurements were performed in consistent with the protocol [9] identified by ISAK. The data related to motor performance were obtained through a group of tests involved in Eurofit Test Battery and other standard tests [20, 27].

Body weight (BW) was measured through an electronic scale with a sensitivity of 0.1 $\mathrm{kg}$. Stature and sitting height were measured by Seca213 Stadiometer. Manouvrier Index was determined using the following formula: (Body Height - Sitting Height/Sitting Heigth) x 100. Arm span, arm (relaxed, flexed and tensed) waist, hip and calf circumferences were measured with anthropometric tape (Cescorf-brand). The breadths of Humerus and Femur were measured with caliper (Cescorf-brand). In skin fold thickness, a Baseline-brand Skinfold Caliper $(0.2 \mathrm{~mm})$ was used. Measurements were performed at the right side of the body (triceps, subscapula, biceps, iliac crest, supraspinale, abdomen, femur and calf regions). Sum of 8 skinfolds was also determined. In addition, during measurements of body fat percentage $(\mathrm{BF} \%)$ the formulas developed by Slaughter for girls and boys were used [3].

Hand grasping strengths were measured by Baseline-brand hand dynamometer in terms of $\mathrm{kg}$. Flexibility test values were obtained by measuring angles in degrees while standing, standing upright with strained knees, grasping at the nadir with Baseline Bubble Inclinometer placed on back. The height of vertical jumping was measured electronically 
on the Smart Jumping Platform. The best one of the three trials was recorded. The values of balance test were obtained through the number of trials performed (with shoes on) on the Flamingo balance board in order to be able to stand for one minute. Arm swiftness, Tapping test, was performed by two discs $(20 \mathrm{~cm}$ in diameter) placed $80 \mathrm{~cm}$ apart on a table with 80 $\mathrm{cm}$ height. One hand was held stationary in the middle and other hand's 25 rotation time on the discs was measured with $1 / 10 \mathrm{sec}$ sensitivity.

Agility, Pro-Agility Test values (participant is at the start position on the centerline of the racetrack, when ordered he/she runs rapidly to the right side and touches the line 5 yards ahead with the right hand and turns rapidly touches the line available 10 yards behind with the left hand and then returns and completes the test by reaching the starting line 5 yards behind) were measured by Smart Speed electronic chronometer. The better one of the two trials was recorded. Throwing ball backward test values (subject takes the position by turning his/her back toward the direction he/she will shoot. After he slightly bent his knees, he strains his body rapidly and throws the ball which he held with two hands in front of him backward) were measured by meter tape. The best one of the three trials was recorded.

$20 \mathrm{~m}$ speed running test values were measured through Smart Speed electronic chronometer with $1 / 100 \mathrm{sec}$ sensitivity. The better one of the two trials was recorded. Speed bounce test, was performed on the $20 \mathrm{~cm}$ high sponge hurdle on a synthetic platform. Each leap performed with double legs towards right and left sides on the hurdle for $20 \mathrm{sec}$ was counted and recorded. The endurance Shuttle Run Test is a test where participants move from one line to the other one on a $20 \mathrm{~m}$ racetrack, change directions by returning back and speed up according the signal consistent with test protocol. Here the purpose is to sustain the race rhythm as long as possible. Those who received three warnings due to not keeping up with the rhythm of the signal are excluded from test. The $20 \mathrm{~m}$ racetrack completed by each child during test period was taken into consideration.

For each age, the data of those who were born within the first three months of the year (Group I) were compared with of those who were born within the last three months of the year (Group II) by considering quarterly periods of the year [25]. In statistical analysis of data the MedCale statistics program (t-test) was used and the differentiation and alteration percentages between two periods were studied.

\section{Result}

For each age, the data of those who were born within the first three months of the year (Group I) were compared of those who were born within the last three months of the year (Group II) by considering quarterly periods [25] and the significance levels of differentiation between two periods are given in Table 1 and Table 2 separately for girls and boys $(\mathrm{p} \leq 0.001, \mathrm{p}=0.05)$. 
Table 1. In Turkish children (girls $\mathrm{N}=601$ ) between 8 and 12 years of age, the RAE on anthropometric characteristics and motor performances.

\begin{tabular}{|c|c|c|c|c|c|}
\hline Parameters & $\begin{array}{l}\text { Age } 12 \\
n=62\end{array}$ & $\begin{array}{l}\begin{array}{l}\text { Age } 11 \\
\mathrm{n}=94\end{array} \\
\end{array}$ & $\begin{array}{l}\text { Age } 10 \\
n=114\end{array}$ & $\begin{array}{l}\text { Age } 9 \\
n=94\end{array}$ & $\begin{array}{l}\text { Age } 8 \\
\mathrm{n}=59\end{array}$ \\
\hline Stature $(\mathrm{cm})$ & & $\mathrm{p}=0.0215^{*}$ & $\mathrm{p}=0.0077^{* *}$ & $\mathrm{p}=0.0225^{*}$ & \\
\hline Sitting Height $(\mathrm{cm})$ & & $\mathrm{p}=0.0410^{*}$ & $\mathrm{p}=0.0363^{*}$ & $\mathrm{p}=0.0175^{*}$ & \\
\hline Arm Span $(\mathrm{cm})$ & & $\mathrm{p}=0.0494^{*}$ & $\mathrm{p}=0.0423^{*}$ & $\mathrm{p}=0.0014^{* *}$ & \\
\hline Calf Girth (maximum) $(\mathrm{cm})$ & & $\mathrm{p}=0.0213^{*}$ & & & \\
\hline Right Hand's Grasping Strength $(\mathrm{kg})$ & & & & & $\mathrm{p}=0.0498^{*}$ \\
\hline Vertical Jump (cm) & & $\mathrm{p}=0.0360 *$ & & & \\
\hline Arm Swiftness (1/10 sec.) & & & & $\mathrm{p}=0.0167^{*}$ & \\
\hline Agility (1/10 sec.) & & $\mathrm{p}=0.0371 *$ & & & $\mathrm{p}=0.0156^{*}$ \\
\hline Backward Ball Throwing (m) & & $\mathrm{p}=0.0002 * * *$ & $\mathrm{p}=0.0336^{*}$ & & \\
\hline $20-\mathrm{m}$ Speed $(1 / 100 \mathrm{sec})$. & & & & & $\mathrm{p}=0.0006^{* * *}$ \\
\hline Speed Bounce $(\mathrm{n} / 20 \mathrm{sec})$ & & $\mathrm{p}=0.0161 *$ & & & \\
\hline
\end{tabular}

$* \mathrm{p}=0.05 \quad * * \mathrm{p}=0.01 \quad * * * \mathrm{p} \leq 0.001$,

Table 2. In Turkish children (boys $\mathrm{N}=601$ ) between 8 and 12 years of age, the RAE on anthropometric characteristics and motor performances.

\begin{tabular}{|c|c|c|c|c|c|}
\hline Parameters & $\begin{array}{l}\begin{array}{l}\text { Age } 12 \\
n=101\end{array} \\
\end{array}$ & $\begin{array}{l}\text { Age 11 } \\
n=122\end{array}$ & $\begin{array}{l}\text { Age 10 } \\
n=132\end{array}$ & $\begin{array}{l}\text { Age } 9 \\
\mathrm{n}=122\end{array}$ & $\begin{array}{l}\text { Age } 8 \\
\mathrm{n}=124\end{array}$ \\
\hline Body weight (kg) & $\mathrm{p}=0.0097 * *$ & & $\mathrm{p}=0.0343^{*}$ & $\mathrm{p}=0.0235^{*}$ & \\
\hline Stature $(\mathrm{cm})$ & & & & $\mathrm{p}=0.0001 * * *$ & \\
\hline BMI $\left(\mathrm{kg} / \mathrm{m}^{2}\right)$ & $\mathrm{p}=0.0162 *$ & & $\mathrm{p}=0.0334^{*}$ & & \\
\hline Sitting Height $(\mathrm{cm})$ & $\mathrm{p}=0.0251^{*}$ & & $\mathrm{P}=0.0255^{*}$ & $\mathrm{p}=0.0004 * * *$ & \\
\hline MI & & & & $\mathrm{p}=0.0417^{*}$ & $\mathrm{p}=0.0214^{*}$ \\
\hline $\operatorname{Arm} \operatorname{Span}(\mathrm{cm})$ & & & & $\mathrm{p}<0.0001 * * *$ & \\
\hline Sum of 8 Skf. (mm) & $\mathrm{p}=0.0112 *$ & & & & \\
\hline $\mathrm{BF}(\%)$ & $\mathrm{p}=0.0089 * *$ & & & & \\
\hline Arm Girth (Relaxed) (cm) & $\mathrm{p}=0.0139 *$ & & $\mathrm{p}=0.0118^{*}$ & & \\
\hline Arm Girth (Flexed and Tensed) (cm) & $\mathrm{p}=0.0094 * *$ & & $\mathrm{p}=0.0133^{*}$ & & \\
\hline Waist Girth $(\mathrm{cm})$ & $\mathrm{p}=0.0056^{* *}$ & & $\mathrm{p}=0.0147^{*}$ & & \\
\hline Hip Girth (cm) & $\mathrm{p}=0.0140^{*}$ & & $\mathrm{p}=0.0071 * *$ & $\mathrm{p}=0.0428^{*}$ & \\
\hline Calf Girth (maximum) (cm) & $\mathrm{p}=0.0399^{*}$ & & $\mathrm{p}=0.0454 *$ & & \\
\hline Humerus Breadth (Biepicondylar) $(\mathrm{cm})$ & $\mathrm{p}=0.0367 *$ & & & & $\mathrm{p}=0.0397 *$ \\
\hline Femur Breadth (Biepicondylar) (cm) & $\mathrm{p}=0.0473 *$ & & $\mathrm{p}=0.0471^{*}$ & & \\
\hline Right Hand's Grasping Strength $(\mathrm{kg})$ & & & & $\mathrm{p}=0.0003 * * *$ & \\
\hline Left Hand's Grasping Strength $(\mathrm{kg})$ & & & & $\mathrm{p}=0.0020 * *$ & \\
\hline Flexibility (Degrees) & $\mathrm{p}=0.0475^{*}$ & & & & \\
\hline Arm Swiftness (1/10 sec.) & & & $\mathrm{p}=0.0013 * *$ & $\mathrm{p}=0.0208^{*}$ & \\
\hline Agility (1/10 sec.) & & $\mathrm{p}=0.0489^{*}$ & & & \\
\hline Backward Ball Throwing (m) & & $\mathrm{p}=0.0474 *$ & $\mathrm{p}=0.0016^{* *}$ & $\mathrm{p}=0.0007 * * *$ & \\
\hline 20-m Speed (1/100 sec.) & & & & $\mathrm{p}=0.0359 *$ & $\mathrm{p}=0.0405^{*}$ \\
\hline Speed Bounce (n/20sec) & & & & $\mathrm{p}=0.0002 * * *$ & \\
\hline Endurance (20m shuttle run) (n) & & $\mathrm{p}=0.0052 * *$ & & & \\
\hline
\end{tabular}

${ }^{*} \mathrm{p}=0.05 \quad * * \mathrm{p}=0.01 \quad * * * \mathrm{p} \leq 0.001$,

\section{Equations and mathematics}

In sports the talent scanning and selection studies are generally carried out on children between 6 and 12 years age and primarily children's anthropometric characteristics, motor skills and technical skills specific to branches are assessed [7, 26]. The trainings and competitions specific to sports branch start early with an earlier specialization and sometimes two different age groups are evaluated in the same category.

There are many factors contributing to RAE (physical, cognitive, emotional and motivational reasons) [7]. In this study, when I. and II. Groups' values were compared in boys based on relative age, RAE-dependent marked differentiations were observed on 
anthropometric properties at 9, 10 and 12 years of age and on motor performance values as well as anthropometric properties at 9,10 and 11 years of age (Table 2).

In biological maturation process the interpersonal difference is a factor that affects growth, performance and physical fitness [10]. The composition of the human body is regulated by genes but is sensitive to environmental, behavioural, and nutritional factors. Interaction between the genetic and non-genetic influences contributes to the variability in body composition observed within and between populations [1]. Anthropometric measures such as circumference, skinfold, and skeletal diameter measurements have been used to assess total and regional body composition [14]. Body weight and height values and growth-development are the most fundamental data used for dietary attitudes and habits [28]. In this study, in-group I and II the RAE-dependent differences between boys' body weights (at 9, 10 and 12 years old) and statures (at 9 years old) were found statistically significant.

The relationship between BMI and BF\% is affected by age, gender, ethnicity, and body build (Deurenberg et al. 1998; Snijder, Kuyf, and Deurenberg 1999) [14]. In this study, there were distinct differences in BMI of boys 10 and 12 years of age depending on RAE in between groups. Besides, in both groups stature values and BMI are found to be close to the mean values of Turkish boys [6]. However, BWs for 8-11 ages were higher than Turkish children mean values for each age group [6]. In this study it was observed that children (each age group) are increasingly gaining weight.

While sums of skinfolds may be used as estimates of overall fatness, specific skinfolds, and ratios between skinfolds, can be used to map subcutaneous fat distribution; even, it was reported that the sum of skin fold thickness is sufficient [29]. In this study, in $\mathrm{BF} \%$ values of boys RAE varied only at the age of 12 , and according to Lohman et al. (1997)'s the classification determined for 6 to 17 year age span [14], the BF\% values of all boys were seen at medium level. Arm, waist circumferences and skinfold thicknesses are considered as additional measures in evaluation of physical dimensions [22] as an indicator of whole body composition [1]. In this study there were RAE-dependent differences in boys within 10 and 12-year of age. The period of fast growing stature coincides at 12-year of age in boys and 14-year of age in girls (Ross et al. 1977) [26]. It was reported that strength feature can be trained optimally right after the period of fast growing stature phase in girls and $1-1.5$ years after this period in boys [26]. In this study a difference in strength ability was observed in boys at 9, 10 and 11 years of ages.

In both genders, ages between 6 and 10 years are the optimal periods of training for flexibility and emphasis must be put on this ability during period of fast growing stature [26]. In this study, RAE in flexibility parameter was observed at 12-year of age in boys. Neuromuscular maturation plays an important role in motor performance during childhood [10]. When evaluated in terms of biological functions, the one that develops best is biologic adaptation capacity among the nervous system, bone development, cardiovascular system, psychological development and muscle development [8]. In this study, RAE in agility parameter was observed at 11-year of age in boys.

Balance ability is observed between 7 and 10 years of age with very great increase each year. This increase continues at 10 and 13 years of age, reaching almost the most advanced level around 13 years of age. Gender-specific differences are not seen. Along with beginning of puberty, a pause or very little development is seen in balance ability [13]. In this study, in boys at all ages any difference could not be observed between groups. At the first stage of speed skill, girls (6-8 years old) and boys (7-9 years old) and at the second stage girls (11-13 years old) and boys (13-16 years old) can be trained better [26]. In this study any RAE-dependent difference was not observed in 8, 9 and 10-year of age in boys. Endurance can be trained best at the early period of fast growing body height. Aerobic capacity trainings are recommended to be given before reaching the period of fast growing 
body height but aerobic power trainings must be given gradually after the growing rate has started slowing down [26]. In this study any RAE-dependent difference was not observed in 11-year of age boys. In girls, when the values of both groups are compared, at the ages of 9 and 10 (among anthropometric properties) the stature, sitting height and arm span values; at the age of 11, the stature, sitting height, arm span and calf circumference values were found statistically higher in Group I (Table 1).

When motor performance was examined, the right hand's grasping power, agility and speed at the age of 8; arm swiftness at 9, body strength at 10 and leaping power, agility, body strength and leaping power durability at 11 were found statistically significant in Group I. At ages of 8 and 11 any statistically significant difference was not observed between both groups in terms of other anthropometric properties and motor performance levels. At the age of 12 any statistically significant differences could not be seen between both groups in terms of both anthropometric properties and motor performance levels (Table 1). We think that this is a result of the fact that 12-year old girls have reached to a certain maturity after the puberty period. It was suggested that the optimal power development in girls can be trained right after the period of fast growing body height. In girls, the first stage of speed and agility can be trained better at the ages of 6-8 and the second stage at the ages of 11-13 [26]. Growth rate advances slowly in between 7-10 years of age in girls and 7-12 years in boys (juvenile) [24]. This situation has restricted the great differences that may occur in our data. However, the studies which could be carried out with different and larger groups may provide more certain information.

Finally, an effect of relative age was observed on anthropometric characteristics and motor performances of 8-12 years old Turkish children. Talent selection, identification and development programs must be multidimensional in a dynamic/prolonged process. Researchers, trainers, families, sports managers and organizers are advised to take into account RAE.

\section{References}

1. Zemel, B. Body composition during growth and development, In: Human Growth and Development", Edited by: Noel Cameron, Elsevier Science (USA), p. 271-291., (2002).

2. Wattie, N., Cobley, S., \& Baker, J. Towards a unified understanding of relative age effects. Journal of Sports Sciences, 26, 1403-1409., (2008).

3. Slaughter, M. H., Lohman, T. G., Boileau, R. A., Horswill, C. A., Stillman, R. J., Van Loan, M. D., \& Bemben, D. A. Skinfold equation for estimation of body fatness in children and youth. Hum Biol. 60, 709-23., (1988).

4. Schorer, J., Wattie, N., \& Baker, J. R. A new dimention to relative age effects: constant year effects in German youth handball, Plos one, 8, 4, 1-7, e60336., (2013).

5. Rummenich, J. N., \& Rogol, A. D. Physiology of growth and development: Its relationship to performance in the young athlete, Clinics in Sports Medicine, 14, 483501., (1995).

6. Neyzi, O., Günöz, H., Furman, A., Bundak, R., Gökçay, G., Darendeliler, F., \& Baş, F. In Turkish Children body weight, tallness, head circumference and body mass index reference values. Children's Health and Diseases Journal, 51:1-14., (2008).

7. Musch, J., \& Grondin, S. Unequal competition as an impediment to personal development: a review of the relative age effect in sport. Developmental Review, 21 (2), 147-167., (2001).

8. Martin, D. Training im Kindes und Jugendalter, Schondorf, Blv Sportwissenschaft, p. 38., (1988). 
9. Marfell-Jones, M. J., Olds, T., Stewart, A. D., \& Carter, L. International Standards for Anthropometric Assessment, Potchefstroom, South Africa., (2006).

10. Malina, R. M., Bouchard, C., \& Bar-Or, O. Growth, maturation and physical activity (2nd ed.). Champaign, Human Kinetics., (2004).

11. Leblanc, J., \& Dickson, L. Children and Sport, Edited by Gazanfer Kemal Gül (Translated by Deniz Erben, Tanju Bağırgan) Sport Publishing House and Book Store, Ankara. p.117., (2011).

12. Kunst, C. \& Florescu, C. The main factors for performance in wrestling. Bucharest: National Sports Cou., (1971).

13. Hirtz, P. Koordinative Fehigkeiten im Shulsport, Berlin, Ost Blv Sportvissenchaft, p. 214-215., (1985).

14. Heyward, V. H. (2006). Advanced fitness assessment and exercise prescription", 5th ed., Human Kinetics, USA, p. 171,198.

15. Helsen, W. F., Winckel, J. V., \& Williams, A. M. The relative age effect in youth soccer across Europe, Journal of Sports Sciences, June; 23 (6): 629-636., (2005).

16. Harre, D. The fundamental characteristics of development period training. Inside; Children and Sport, Translated and Edited by Gazanfer Kemal Gül, Tanju Bağırgan, Sport Publishing House and Book Store, Ankara. p.159., (2011).

17. Grondin, S., Deschaies, P., \& Nault, L. P. Trimesters of birth and school output. Apperent Social, 16:169-74., (1984).

18. Gil, S. M., Badiola, A., Letona, I. B., Lili, J. Z., Gravina, L., Concejero, J. S., Lekue, J. A., \& Granados, C. Relationship between the relative age effect and anthropometry, maturity and performance in young soccer players. Journal of Sports Sciences, 32, 5, 479-486., (2014).

19. Delorme, N., Boiché, J., \& Raspaud, M. Relative age effect in elite sports: Methodological bias or real discrimination? European Journal of Sport Science, 10, 9196., (2010).

20. Committee of experts On Sports Research. Handbook for the Eurofit Test of Physical Fitness Rome, p.9-12., (1988).

21. Cobley, S., Baker, J., Wattie, N., \& McKenna, J. M. Annual age-grouping and athlete development: A meta-analytical review of relative age effects in sports, Sports Medicine,39: 235-256., (2009).

22. Chumlea, W. C., \& Guo, S. S. The assessment of human growth, In: Human Growth and Development. Edited by: Noel Cameron, Elsevier Science (USA), s.352., (2002).

23. Bompa, T. O. The training theory and method in periods, Trans. by İlknur Keskin, A. Burcu Tuner, Hatice Küçükgöz, Tanju Bağırgan, Sport Publishing House and Book Store, Ankara, p.266-284., (2011).

24. Bogin, B. A. The evolution of human growth. In: Human Growth and Development. Edited by: Noel Cameron, Elsevier Science (USA), p.300., (2002).

25. Barnsley, R. H., Thompson, A. H., \& Legault, P. Family planning: football style. The RAE in football. International Review for the Sociology of Sport, 27, 77-88., (1992).

26. Balyi, I., Cardinal, C., Higgs, C., Norris, S., \& Way, R. Long-Term Athlete Development - Canadian Sport for Life. Resource Paper V2, Published by the Canadian Sport Centers, p. 23-27., (2005).

27. Akgün, N., Ergen, E., Ertat, A., İşlegen, Ç., Çolakoğlu, H., \& Emlek, Y. Preliminary results of motor fitness, cardiorespiratory fitness and body measurrements in Turkish Children. 5th European research seminar on testing physical fitness. Formia: Committee for the Development of Sport. 25, 51., (1986).

28. Adams, J. B., \& Adams J. B. Practical applications and limitations of tracking body mass index in schools. JOPERD, 80, 4, 14-17., (2009). 
29. Abernethy, P., Olds, T., Eden, B., Neill, M., \& Baines, L. Anthropometry, health and body composition, In: Anthropometrica. Edited by: Kevin Norton \& Tim Olds, UNSW press, Australia, p.376., (1996). 